\title{
FOURTEENTH ANNUAL GENERAL MEETING
}

of all creeds. Many of the children are assault cases and need healing in body, mind and spirit.

We aim at treating the whole child-at giving them a normal child life in a Christian atmosphere.

Strict discipline has always to be maintained, but we want them to forget fear.

Besides our excellent medical staff we have one asset of immense value, a real " Nannie," and are able to keep an individual touch on every child, and give help physically, mentally and morally. The school, too, is a very distinctive feature of the Home.

From the beginning Mr. Davies Colley, of Guy's, has been Treasurer and mainstay, and the L.C.C. has been most kind.

\section{E. Bunyon,}

Chairman.

\section{AN IMPRESSION OF THE CHILDREN'S MEDICAL HOME, WADDON}

THE medical practitioner faced with the care of vulvovaginitis in little girls may well feel all the social emotions purged by pity and terror-pity for the innocent victim and terror for its possible consequences to other small innocents. The physical injury carries with it a psychological wound, all the deeper for the very impressionable age at which it has been inflicted, and the prolonged local treatment has unavoidably further special physiological and psychological dangers, to be counteracted only by humane assiduous care demanding the highest skill and the happiest moral surroundings.

Few homes among hospital patients can provide this ; and too often the best meaning institutional surroundings and discipline bleakly annul in the realm of the spirit the most skilful and unremitting individual care. It is therefore a welcome surprise to find in an institution the obvious and unmistakable proofs-in its children-of affectionate personal care inextricably interwoven with the happiest moral surroundings.

The Children's Medical Home at Waddon is an oldfashioned country villa in its own wide gardens. Its furnishing is simple, it is well lighted and home-like ; and clean without the pervading odour of newly scrubbed boards, Its children are plainly healthy, vigorous and 


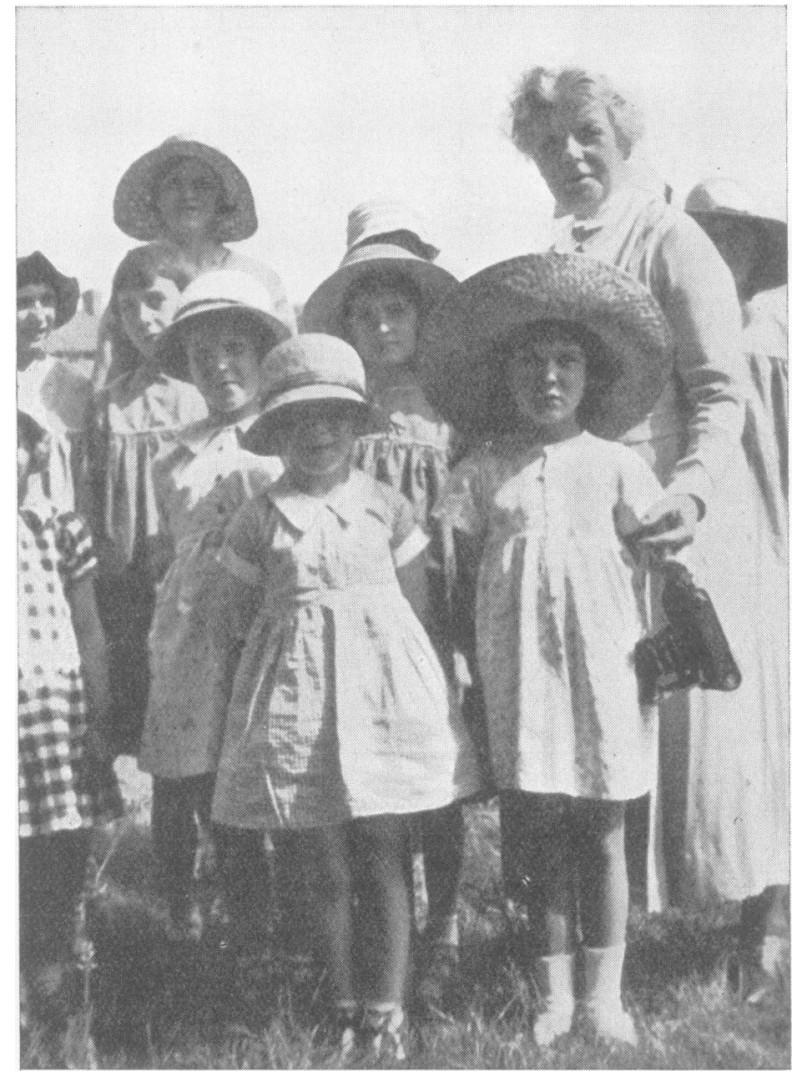

The Matron with some of her charges.

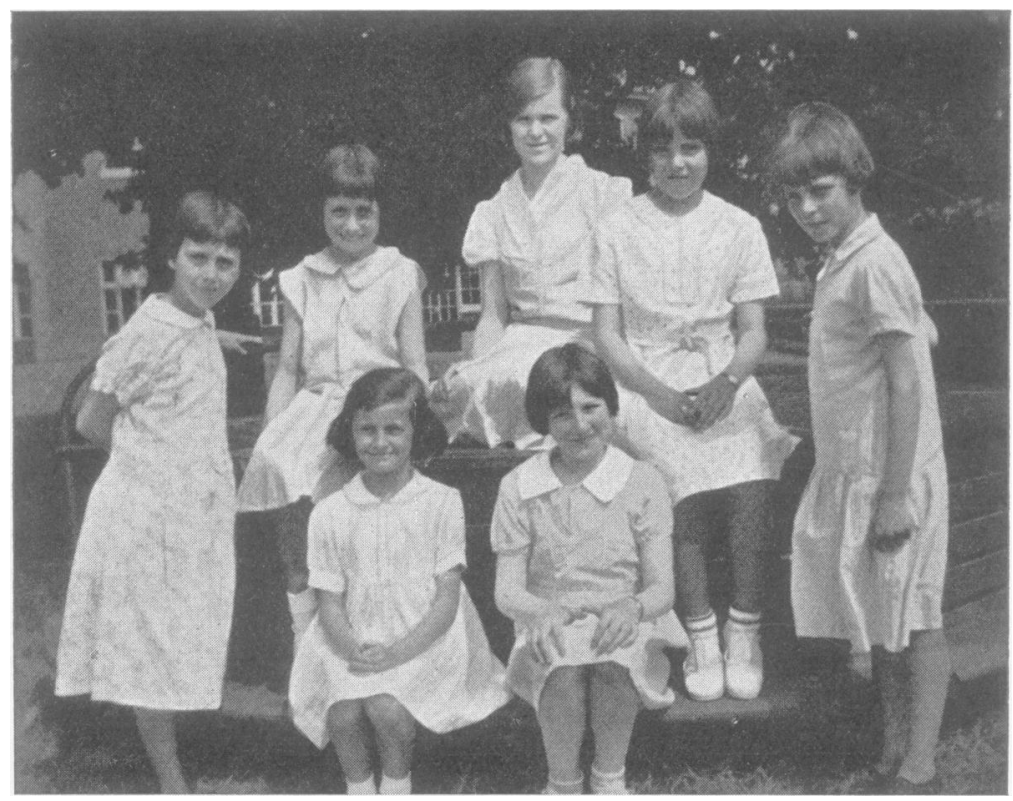

What are they thinking? 


\section{FOURTEENTH ANNUAL GENERAL MEETING}

bright, and as plainly content and happy. They are schooled, and the schooling has a religious foundation. Their natural instincts for possession and rivalry and their natural propensities to seek pleasure are, with the touch of genius, used to teach them to discipline themselves; and so exactly and successfully that no case of crossreinfection has ever occurred there, though the children live and play together.

To see this children's home and to watch its children is a valuable and gratifying experience to all medical practitioners. All of us fortunate enough to have had this experience believe that our school teachers could do no better than to study the ingenious, kindly and humorous methods devised and practised there, with such happy results, by the Matron and her Nurses.

H. M. HANSCHELL.

The President and Council of The Medical Society for the Study of Venereal Diseases wish to express to Miss Bunyon, Dr. Kathleen Brown, Mrs. Woolner, the Matron, and the other Officers of the Children's Medical Home their sincere appreciation of the hospitality extended to its members on the occasion of the Annual General Meeting. 